\title{
Wet and gassy zones in a municipal landfill from P- and S-wave velocity fields
}

\author{
Laura Amalia Konstantaki ${ }^{1}$, Ranajit Ghose ${ }^{2}$, Deyan Draganov², and Timo Heimovaara ${ }^{2}$
}

\begin{abstract}
The knowledge of the distribution of leachate and gas in a municipal landfill is of vital importance to the landfill operators performing improved landfill treatments and for environmental protection and efficient biogas extraction. We have explored the potential of using the velocity fields of seismic S- and P-waves to delineate the wet and gassy (relatively dry, gas/air-filled) zones inside a landfill. We have analyzed shallow S- and P-wave reflection data and seismic surface-wave data acquired at a very heterogeneous landfill site, where biogas was extracted. A joint interpretation of the independently estimated velocity fields from these various approaches has allowed us to localize anomalously low- and high-velocity zones in the landfill. From the complementary information provided by $\mathrm{P}$ - and S-wave velocity fields, we have inferred the leachate-bearing wet zones and the gassy zones inside the landfill. Independent measurements of gas flow and mechanical tip resistance to waste deformation validate our seismic interpretations.
\end{abstract}

\section{INTRODUCTION}

Landfills are generally very heterogeneous bodies, in which complex biogeochemical reactions occur that produce leachate and biogas. The treatment technologies and the prediction of the emissions from a landfill with time can be improved when quantitative information is available about the biogas and the leachate pathways. Nowadays, wells are used to collect the biogas for protection of the environment and for energy production (Themelis and Ulloa, 2007). For the estimation of the future biogas emissions, precise biogas measurements and knowledge of the biogas distribution inside the landfill are important. The existing methods for measuring biogas concentrations (e.g., soil-core measurements and static closed chamber measurements) are not sufficiently accurate, and the results of the present-day emission-prediction models are contradictory when used individually for the same landfill (Scharff et al., 2011). Soil-gas measurements provide biogas distributions, but only at the surface (Nolasco et al., 2008). To obtain biogas distributions at depth, wells have to be drilled, which is expensive and invasive. Knowledge of the distribution of biogas in the landfill can help to improve the capture of biogas through, for instance, improved placement of the gas-extraction wells. Electrical resistivity (ER) measurements have been used to map gas (relatively dry, gas/airfilled) pathways, but additional information (e.g., temperature distribution) is needed to improve their interpretation (Rosqvist et al., 2011). Although this approach has potential, the results are so far qualitative (Johansson et al., 2011).

Leachate follows preferential flow pathways, which are strongly affected by the waste composition and compaction (Sormunen et al., 2008). Mainly mass-balance modeling is used to estimate the leachate emission, and mathematical models are used to explain the preferential flow paths (e.g., double-porosity model). Geophysical measurements are one of the few methods that are able to image the leachate pathways, with ER tomography (ERT) being the most commonly used method for this purpose (Rosqvist et al., 2005). However, artifacts, uncertainty, and limited resolution are outstanding issues with the ERT method (Jolly et al., 2011). Konstantaki et al. (2015a) use a combination of S-wave reflection and ERT methods to localize leachate pockets. S-waves are sensitive to rigidity and density variations in the near-surface soils and landfill materials (Ghose, 2003; Ghose and Goudswaard, 2004; Choudhury and Savoikar, 2009), but not to their fluid (liquid or gas) content. Additional information (e.g., ER measurements) is necessary for a complete interpretation of the leachate pathways.

In oil and gas geophysical investigations, the ratio of $\mathrm{P}$ to S-wave velocities $\left(V_{\mathrm{P}} / V_{\mathrm{S}}\right)$ and hence Poisson's ratio

Manuscript received by the Editor 30 October 2015; revised manuscript received 22 May 2016; published online 07 September 2016.

${ }^{1}$ Formerly Delft University of Technology, Department of Geoscience and Engineering, Delft, The Netherlands; presently Eawag (Swiss Federal Institute for Environmental Science and Technology), Department Lib4Ri Library, Dubendorf, Switzerland. E-mail: laura.konstantaki@gmail.com.

${ }^{2}$ Delft University of Technology, Department of Geoscience and Engineering, Delft, The Netherlands. E-mail: r.ghose@tudelft.nl; d.s.draganov@tudelft.nl; t.j.heimovaara@tudelft.nl.

(C) 2016 Society of Exploration Geophysicists. All rights reserved. 
$\left(v=0.5\left[\left(V_{\mathrm{P}} / V_{\mathrm{S}}\right)^{2}-2\right] /\left[\left(V_{\mathrm{P}} / V_{\mathrm{S}}\right)^{2}-1\right]\right)$ have been used for many decades as an indicator of fluid-bearing zones. But this use has not been widespread in the investigation of near-surface soil layers $(0-50 \mathrm{~m})$. However, because $\mathrm{P}$-waves are sensitive to the fluid content in soil, $V_{\mathrm{P}} / V_{\mathrm{S}}$ should also be useful in shallow subsoil investigation, as reported in several earlier studies identifying gas- or liquid-bearing zones in the near surface (Westbrook et al., 2008; Konstantaki et al., 2013b). The $V_{\mathrm{P}} / V_{\mathrm{S}}$ ratio is very low when gas is present, whereas the ratio increases when water or leachate gradually replaces the gas (Rojas et al., 2005). Carpenter et al. (2013) use $V_{\mathrm{P}} / V_{\mathrm{S}}$ and hence Poisson's ratio to infer the low strain or dynamic properties of a landfill, but not specifically the distribution of dry, gas-bearing zones and wet zones.

The seismic-wave velocities depend on the ratio between the elastic modulus and the density. The modulus and density effects compete with each other, and as a result, the velocity can go up or down. The dependence of the P- and S-wave velocities on the properties and saturation of the fluid(s) that fill the pore spaces in soils and rocks is a well-studied topic. Saturation dependence tends to be larger for softer materials. The S-waves are hardly sensitive to the presence of fluid, but they are more sensitive to grain contacts, which primarily control the shear modulus (rigidity) of soils. However, P-waves are greatly influenced by the pore-fluid content. On the other hand, a change in pore-fluid saturation causes a change in the effective pressure, which in turn affects $V_{\mathrm{P}}$ and $V_{\mathrm{S}}$, though to a lesser extent than the effect of fluid itself. Increasing pore pressure softens the elastic frame by opening flaws, tending to lower velocities. In addition, the bulk density relates inversely to $V_{\mathrm{P}}$ and $V_{\mathrm{S}}$. Density increases when going from dry- to water-saturated soil. By taking the ratio $V_{\mathrm{P}} / V_{\mathrm{S}}$, it is possible to get rid of the ambiguity due to density effect versus modulus effect.

As a net effect, it has been found that $V_{\mathrm{P}}$ increases when the water saturation increases, whereas $V_{\mathrm{S}}$ remains constant or even drops slightly (Knight and Nolen-Hoeksema, 1990). When the pores in the soil are filled with water, the density increases (compared with dry or air-filled pore situations), and because no/little changes occur in the shear modulus in this case (Berryman, 1999), excepting the effect of effective stress (Ghose, 2010), $V_{S}$ can slightly decrease. Compared with a dry soil, a water-bearing soil should exhibit higher $V_{\mathrm{P}}$ and unchanged to slightly decreased $V_{\mathrm{S}}$ (in this case, by "unchanged," we mean no change in the value of velocity at a given location compared with its surrounding). In the presence of gas, $V_{\mathrm{P}}$ decreases compared with the value for water-saturated pores (Barton, 2007), whereas $V_{\mathrm{S}}$ remains low and stable or increases slightly - the increase in $V_{\mathrm{S}}$ is due to the decrease in bulk density (Bacon et al., 2003). In summary, a gas-bearing zone in soils is expected to show up as having a very low $V_{\mathrm{P}}$ and low, unchanged to slightly increased $V_{\mathrm{S}}$. Based on the borehole logs and P- and Svelocity images obtained from inversion of crosswell seismic data in unconsolidated soil, Angioni et al. (2003) indeed find very low Pwave velocity and low S-wave velocity in the gas-bearing part of an otherwise water-filled soil column.

The primary goal of this study is to map reliably the heterogeneous subsurface of the landfill. To address this challenging task, we first make use of complementary information from P- and $S$-wave velocity fields. Second, we validate the derived rigidity and density fields by using independent field measurements. As an ancillary objective, we wanted to investigate, in the context of landfill characterization, the benefit of integrating several different methods of estimation of near-surface seismic velocity field, involving body and surface waves. In this paper, we present the velocity fields obtained from the recorded $\mathrm{P}$ - and $\mathrm{S}$-wave seismic reflections and surface-wave data. The velocity fields are obtained by three different methods: (1) analysis of the seismic reflections, taking into consideration distinct scattered field in the data, (2) multichannel analysis of surface waves (MASW), and (3) early waveform inversion for estimation of P-wave velocity at very shallow depths.

\section{FIELD EXPERIMENTS}

In May 2014, we acquired shallow seismic reflection data at a location of the Twence landfill in Hengelo, the Netherlands (Figure 1a). The landfill has an impermeable layer at the bottom to prevent waste and leachate from contaminating the surrounding medium. The bottom of the landfill is located at approximately $14 \mathrm{~m}$ depth. On the top of the landfill, there is a $2 \mathrm{~m}$ soil cover and no impermeable layer. The landfill is operated since 1986 and Twence treats it as a bioreactor (Sponza and A $\breve{g}$ dağ, 2004) — the biogas emitted from the landfill is used for energy production. The landfill contains sludge and shredded household and industrial wastes (R. Nijboer, personal communication, 2015). The site of the present seismic experiments contains mainly organic wastes. The seismic line was parallel to a road (Figure 1a) along which heavy trucks and cars were frequently passing by, causing anthropogenic seismic noise. Works being carried out in nearby buildings for processing the landfill wastes and for energy production added further noise.

In coincident $\mathrm{P}$ - and $\mathrm{S}$-waves reflection profiling (location marked by the white line in Figure 1a), a hammer hitting vertically a metal plate was used as a P-wave source, whereas a hammer hitting a wooden beam horizontally was used as an S-wave source. Data were acquired in two days, during which light to heavy rainfall occasionally disrupted the fieldwork. Single-component $10 \mathrm{~Hz}$ vertical and horizontal geophones were planted at $0.5 \mathrm{~m}$ spacing for $\mathrm{P}$ - and S-waves reflection profiling, respectively. A roll-along mode of data acquisition was used. The acquisition parameters are summarized in Table 1.

For the S-wave, 72 geophone channels were available per shot, and the total number of shots (source locations) was 34 . The source interval was $1 \mathrm{~m}$. The source moved from 0 to $33 \mathrm{~m}$ along the line, whereas the first horizontal geophone was at $10 \mathrm{~m}$ and the last one was at $57.5 \mathrm{~m}$. The first 24 channel geophone cable was rolled forward to the end part of the line when the source reached $21.5 \mathrm{~m}$. The vertical stack count at each $\mathrm{S}$-wave source location was eight. The temporal sampling for $\mathrm{S}$-wave data was $0.5 \mathrm{~ms}$ (Nyquist frequency $1 \mathrm{kHz}$ ) and the total recording time was $1 \mathrm{~s}$.

For the P-wave, 48 vertical geophones were used, and the total number of shots (source locations) was 78 . The source moved at $1 \mathrm{~m}$ interval between location 0 and $77 \mathrm{~m}$ along the seismic line. The nearest-offset 24 channel geophone cables were rolled forward three times to the end of the second geophone cable - when the source reached $21.5,34$, and $46.5 \mathrm{~m}$ along the line. The first vertical geophone was located at $10 \mathrm{~m}$, and the last one was located at $69.5 \mathrm{~m}$ field locations. The time sampling for P-wave data was $0.25 \mathrm{~ms}$ (Nyquist frequency $2 \mathrm{kHz}$ ), and the recording time was $1 \mathrm{~s}$.

In addition to seismic data, at the same site mechanical tip resistance to waste deformation was measured along a line parallel to the seismic line. The Multriwell is a biogas-extraction system, in which flexible wells in the vertical and horizontal directions are installed, creating a close-knit grid for gas collection. During the installation 
of the vertical (type V) wells, the depth and the encountered mechanical tip resistance of the waste are recorded. Type $\mathrm{V}$ wells are pushed into the waste with the help of a crane (Timmermans and Hilebregt, 2012; Overzet and Woelders, 2013). The nearest mechanical tip-resistance line was 1-2 m separated from the seismic line and ran nearly parallel to the seismic line (it did not cross the seismic line). The first well measuring mechanical tip resistance of the waste material was located at $5 \mathrm{~m}$ before the first source position and the last one at $67 \mathrm{~m}$ (Figure 1b). The interval between these wells was $3 \mathrm{~m}$, resulting in a total of 21 well locations within the stretch of both the seismic lines.

\section{OBTAINING P- AND S-WAVE VELOCITY FIELDS IN THE LANDFILL: MULTIPLE APPROACHES}

The processing of seismic data obtained at a landfill site is challenging due to the very heterogeneous nature of the subsurface, in addition to the noisy nature of the data. The presence of many scatterers in the landfill usually makes the estimation of the seismic velocity field a daunting task. For a greater confidence, we estimated the velocity field by three independent approaches - careful analysis of seismic reflections focusing on the scatterers in the

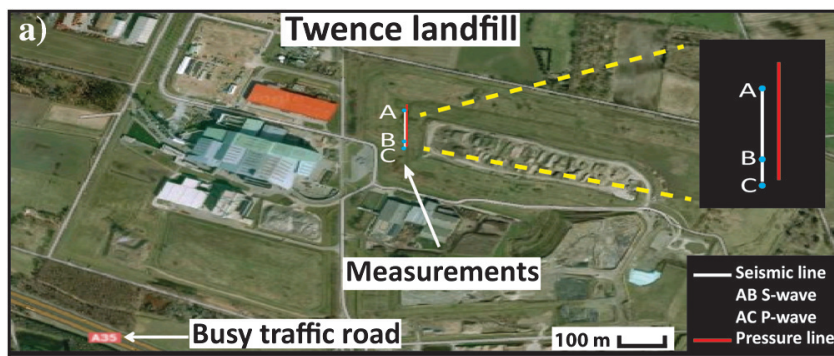

b) Data-acquisition geometry
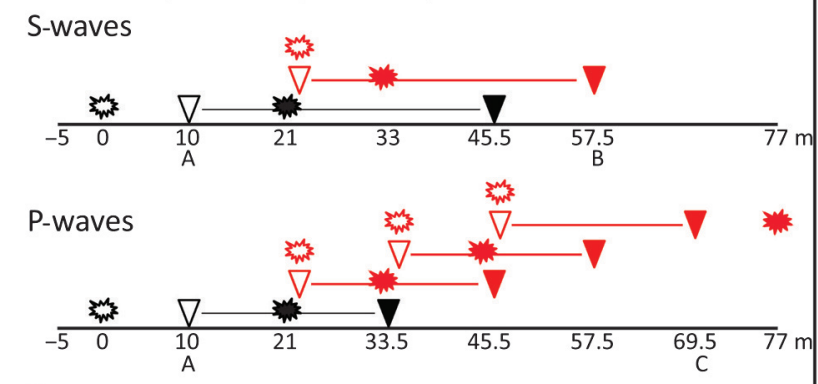

Pressure

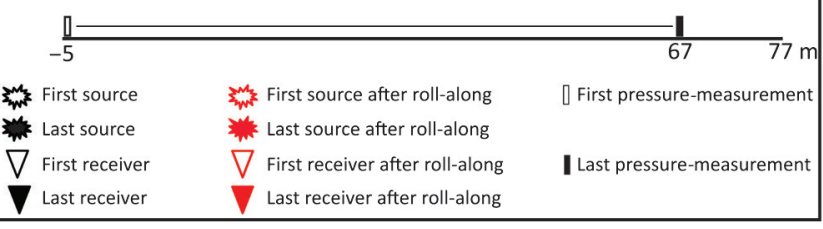

Figure 1. (a) A map of the Twence landfill. The white line indicates the location of the coincident S- and P-wave seismic profiles; the red line indicates the location of mechanical tip-resistance pressure measurements. The mechanical tip-resistance measurements were carried out along a line adjacent to $(<2 \mathrm{~m}$ separation from $)$ the seismic lines. (b) Geometry for S-wave, P-wave, and mechanical tipresistance measurements. Roll-along data acquisition was carried out for seismic profiling. The source and receiver spacing was 1 and $0.5 \mathrm{~m}$, respectively. For the mechanical tip-resistance measurements, the well spacing was $3 \mathrm{~m}$. data, MASW, and early arrival waveform inversion. These results will be discussed next.

\section{Velocity fields from shallow $P$ - and S-wave reflections}

In Konstantaki et al. (2015a), a four-step iterative processing strategy is presented to obtain the velocity field from shallow seismic reflection data acquired on a heterogeneous landfill (see Figure 6 in that publication). We use the same strategy for the data sets acquired at the Twence landfill. This strategy tracks a particular event (diffraction or reflection) in shot gather, common midpoint (CMP) supergather and stacked section, and attempts to find the best possible velocity for this event. Here, we briefly outline the main processing operations. After geometry installation, the shot gathers are edited (dead/noisy traces killed and trace-polarity reversed, when needed), and then geometric-spreading and intrinsic-loss corrections are applied. This is followed by spectral shaping and band-pass filtering. Spectral shaping helps to reduce the surface-wave energy and improve the resolution. Frequencies more than $65 \mathrm{~Hz}$ are eliminated as those contributed primarily to the noise. Figure $2 \mathrm{a}$ and $2 \mathrm{~d}$ shows representative S- and P-waves raw shot gathers, respectively; here, the sources are at a horizontal distance of $26 \mathrm{~m}$. It can be noticed at first sight by looking at the first arrivals in the raw shot gathers that the $\mathrm{P}$-wave velocity is only slightly larger than the $\mathrm{S}$-wave velocity, a striking observation for this site. Figure $2 b$ and $2 e$ shows the same shot gathers but after correction for spherical divergence and intrinsic attenuation, and application of spectral shaping and bandpass filtering. After these processing steps, a careful top mute is applied to remove the direct arrivals, refractions, and surface waves as much as possible (as velocity filtering was not realizable for this data set without losing/distorting useful signals). A bottom mute is applied to the S-wave data to remove surface-wave arrivals from another source. During the S-wave data acquisition, workers were installing gas pipes at approximately $25 \mathrm{~m}$ distance perpendicular to the seismic line (in the middle of the line). This has possibly caused the surface waves arriving at later times, prominent in S-wave data. The results are shown in Figure $2 \mathrm{c}$ and $2 \mathrm{f}$ for the $\mathrm{S}$ - and P-waves, respectively.

Considering the two-way traveltime (TWT) and the moveout velocity, we interpret the reflection event at approximately $250 \mathrm{~ms}$ TWT in the S-wave data and at $175 \mathrm{~ms}$ TWT in the P-wave data to correspond to the bottom of the landfill (approximately $14 \mathrm{~m}$ depth). These are shaded in yellow in Figure $2 \mathrm{c}$ and $2 \mathrm{f}$. Note that, below the landfill, the reflection events from soil-layer boundaries are more prominent than those within the landfill. It is, however,

Table 1. Acquisition parameters for the $P$ - and S-wave reflection data.

\begin{tabular}{lcc}
\hline & \multicolumn{1}{c}{ S-waves } & P-waves \\
\hline Source & $\begin{array}{c}\text { Horizontal (S-wave) } \\
\text { vibrator hammer }\end{array}$ & P-wavehammer \\
Source spacing & $1 \mathrm{~m}$ & $1 \mathrm{~m}$ \\
Receiver & Horizontal $10 \mathrm{~Hz}$ & Vertical 10 Hz \\
& geophones & geophones \\
Receiver spacing & $0.5 \mathrm{~m}$ & $0.5 \mathrm{~m}$ \\
Time sampling & $0.50 \mathrm{~ms}$ & $0.25 \mathrm{~ms}$ \\
Total time & $1 \mathrm{~s}$ & $1 \mathrm{~s}$ \\
\hline
\end{tabular}


clear that also within the landfill, there is a layered structure, indicated by the presence of laterally continuous hyperbolic reflection events in the shot gathers. We focus on the landfill itself, and hence we look at events shallower than the landfill bottom. Scatterers inside the landfill can be identified in the preprocessed shot gathers (marked in red and blue in Figure 2c and 2f).

As in Konstantaki et al. (2015a), the velocities are picked, such that the scatterers (presumably the higher density areas that act as obstructions to fluid/leachate flow) are imaged best. This is done in an iterative manner while examining a chosen shot gather, CMP supergather, and the stacked section. Figure 3 a shows the S-wave stacked section. Figure $3 \mathrm{~b}$ shows the same section with interpretation of many possible scatterers (marked in red and blue) and the geologic layer boundaries (gray shaded). The lower boundary of the top-soil cover of the landfill, known to be at approximately $2 \mathrm{~m}$ depth, is imaged well in the S-wave reflection section (Figure $3 b$ ). The landfill body is dominated by the presence of many scatterers, whereas the natural soil below the landfill has predominantly a layered structure (especially distinct on the right side of the section between 21.5 and $35 \mathrm{~m}$ lateral distance). The discontinuity of seismic reflectors below the landfill on the left side (horizontal distance a) Horizontal distance $(\mathrm{m})$
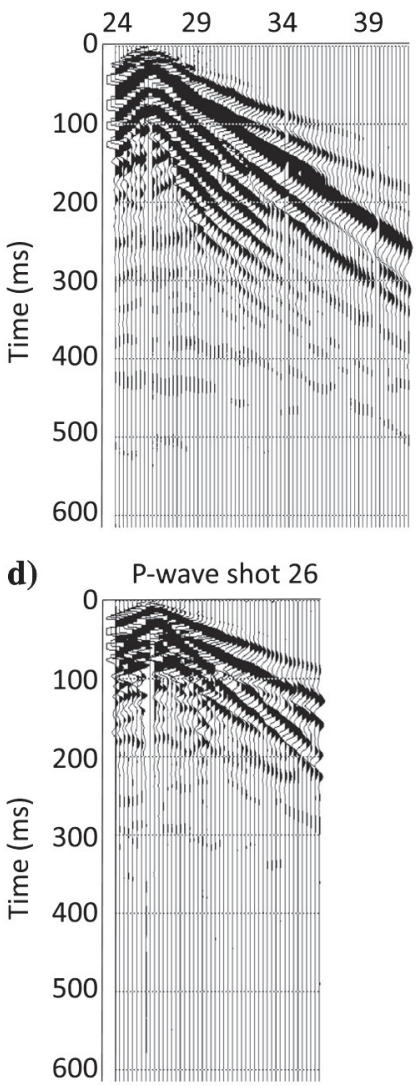

b) S-wave shot 26

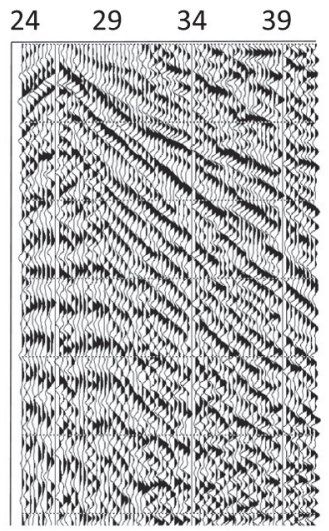

e) P-wave shot 26

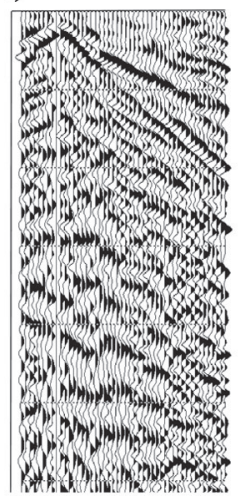

c) S-wave shot 26

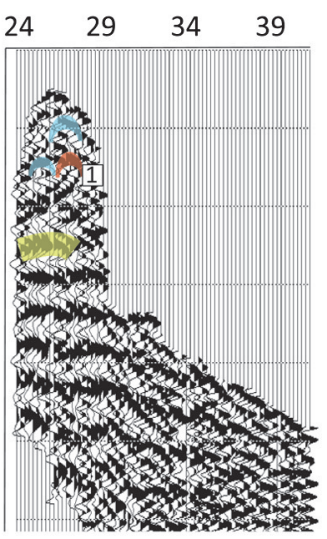

f) P-wave shot 26

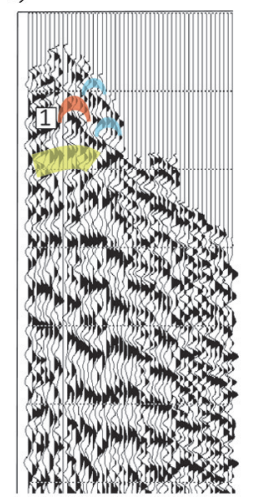

Figure 2. Representative S- and P-wave shot gathers; source location at $26 \mathrm{~m}$ horizontal distance: (a and d) raw data; (b and e) data after correction for spherical divergence, intrinsic loss, spectral shaping, and bandpass filtering; (c) S-wave data after top and bottom muting; and (f) P-wave data after top muting. The red hyperbola illustrates a typical scattering event that is present in S- and P-wave data; the blue hyperbolae — other scattering events, in a noisy environment. The yellow-shaded area indicates the reflection from the bottom of the landfill. between 0 and $21.5 \mathrm{~m}$ ) is because of the presence of surface waves in the stacked section, which is due to the restricted CMP fold till the end of the first geophone cable (see the acquisition geometry plotted at the bottom of Figure 3). The absence of energy or gap at approximately 7-9 $\mathrm{m}$ horizontal distance and $200 \mathrm{~ms}$ TWT in S-wave stacked section (Figure 3 ) is because of the muting

In Figure 4a, the P-wave stacked section is shown; the interpretations are marked in Figure 4b. Using a smooth velocity estimated from the stacking velocity field, we calculate the approximate depth by time-to-depth conversion. Note that the horizontal distance is ferent from that of the S-wave section. Several scatterers, which also distinguishable in the S-wave stacked section, are highin me wave section offers, in general, a lower resolution compared with the S-wave section. The reflectors below the landfill are clearly imaged by the $\mathrm{P}$ waves; these reflectors are more continuous than those in the $\mathrm{S}$-wave stacked section (gray shaded areas less than $13 \mathrm{~m}$ depth). This is due to the difference in the acquisition geometry between $\mathrm{P}$ - and S-wave profiles, caused by time limitation and the unfavourable weather condition. The $\mathrm{P}$-wave data acquisition geometry is plotted in the lower part of Figure 4. The CMP fold is variable, but less than that in the $\mathrm{S}$-wave profile (see the lower panels in Figures 3 and 4).

In Figure 5, we plot the interpreted P- and Swave stacked sections for the same lateral distance and comparable depths for a better understanding of the location of the scatterers. The Swaves offer higher resolution, and they are more sensitive to changes in the soil type. The scatterers are clearly imaged in the S-wave data, whereas their identification is often difficult in the $\mathrm{P}$-wave data. The layer boundaries are imaged in both data sets — in the P-wave data, they appear more continuous.

In Figure 6a and 6b, the interval velocity fields obtained from the velocity analysis (Konstantaki et al., 2015a) of P- and S-wave reflection data, respectively, are shown. Interval velocity is estimated from the root-mean-square (rms) velocity. Note that the color scale is the same for the $\mathrm{P}$ - and $\mathrm{S}$-wave velocity fields. It is striking that the $V_{\mathrm{P}}$ in this landfill is, in general, only slightly higher than the $V_{\mathrm{S}}$. Although the average $V_{\mathrm{S}}$ is in the range of $60-80 \mathrm{~m} / \mathrm{s}$, the average $V_{\mathrm{P}}$ varies between 80 and $100 \mathrm{~m} / \mathrm{s}$ in the landfill. The implication of this will be discussed in detail in the following sections. Examples of the rms velocity picking for reflection events made on CMP supergathers are illustrated in Figure $7 \mathrm{a}-7 \mathrm{c}$ for three locations (marked by the small red circles 
in Figure 6a and 6b), for P- and S-waves. In Figure 7a and 7b, it is visible that the $\mathrm{P}$-wave rms velocity is only $20 \%-30 \%$ higher than the S-wave rms velocity. Figure 7c illustrates the possibility of wrong velocity picking on S-wave CMP supergather in case the far-offset information is missing due to muting of the surface waves. Using only the near-offset information when performing velocity analysis for such shallow zones can result in erroneous velocity picks.

Although $V_{\mathrm{P}}$ depends on the bulk and shear moduli (in addition to density), $V_{\mathrm{S}}$ is dependent only on the shear modulus or rigidity. The black line in Figure $6 \mathrm{~b}$ marks tentatively the boundary between relatively low- and high-rigidity zones in the landfill, as resolved in the $V_{\mathrm{S}}$ field obtained from the seismic reflection data. This line is drawn to examine the pattern of rigidity distribution in the landfill as obtained from $\mathrm{S}$-wave reflection and Love-wave dispersion data sets. The rms velocity of S-waves is affected more by the presence of scatterers, as those scatterers generally have a different stiffness than the surrounding material. Hence, the $V_{\mathrm{S}}$ field can resolve the low- and high-rigidity zones in the landfill better than the $V_{\mathrm{P}}$ field.

a)
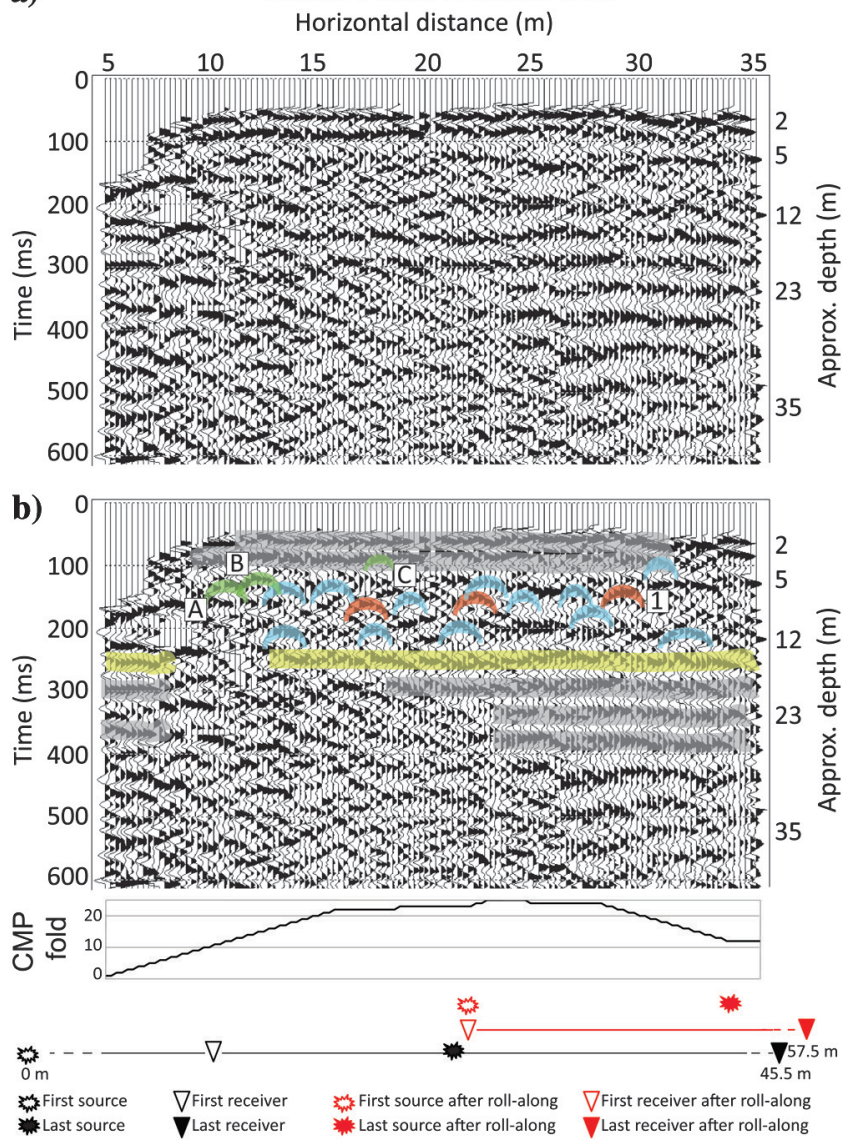

Figure 3. (a) S-wave stacked section and (b) interpreted S-wave section. The color-highlighted hyperbolae show possible scatterers, whereas the gray-shaded areas show reflectors. Red hyperbolae are the ones that are also apparent in the P-wave stacked sections (Figure 4). Scatterer 1 is the one which is interpreted also in the shot gathers (Figure 2). Green hyperbolae correspond to events interpreted in Figure 6. The bottom of the landfill is marked in yellow. The CMP fold distribution and the shot/receiver locations are illustrated in the bottom panels.

\section{Velocity fields from multichannel analysis of surface waves}

Both acquired seismic data sets (P and S) show the presence of strong surface-wave energy (Love and Rayleigh waves, respectively). For a crosscheck of the $V_{\mathrm{S}}$ field obtained from the reflection data analyses, we performed MASW (Park et al., 1999). The inversion of the fundamental-mode surface-wave dispersion was performed for a half-space of $16 \mathrm{~m}$. The details of MASW data processing and inversion, in the context of a heterogeneous landfill, are discussed in Konstantaki et al. (2015a).

The results of MASW for Love and Rayleigh waves are shown in Figure $8 \mathrm{~b}$ and $8 \mathrm{c}$, respectively. The 2D sections are obtained through successive 1D inversions. For a comparison, the velocity field obtained from the S-wave reflection data is plotted in Figure 8a. The color scale is the same for all three panels in Figure 8. A layered velocity model is assumed for the MASW inversion; this does not allow achieving sufficient lateral resolution in the velocity field because it ignores the localized scattered energy in the data (van Wijk and Levshin, 2004). As a landfill is a heterogeneous body with many scatterers, the usual assumption in MASW of a layered velocity model is not appropriate. As expected, the velocity field obtained from the S-wave reflection data shows more details compared with the velocity fields obtained from MASW. Furthermore, the velocity

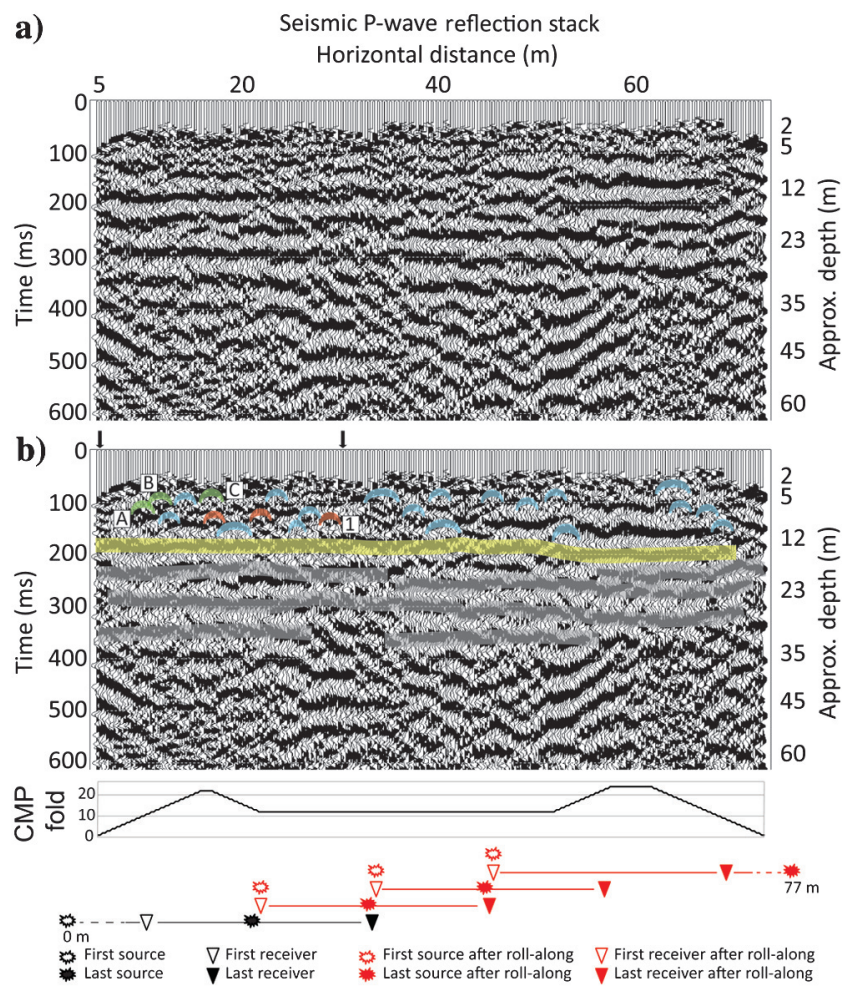

Figure 4. (a) P-wave stacked section and (b) interpreted P-wave section. The color-highlighted hyperbolae show scatterers and the gray-shaded areas show reflectors. Red hyperbolae are the ones that are also apparent in the S-wave stacked sections (Figure 3). Scatterer 1 is the one which is interpreted also in the shot gathers (Figure 2). Green hyperbolae correspond to events interpreted in Figure 6 . The bottom of the landfill is indicated with the yellowshaded area. The two arrows on the top margin of panel (b) mark two ends of the S-wave section. The CMP fold distribution and the shot/receiver locations are illustrated in the bottom panels. 
fields obtained from the Love- and Rayleigh-wave data sets are not the same. The rms errors for the Love- and Rayleigh-wave inversions are aproximately $2 \%-7 \%$ and $2 \%-11 \%$, respectively. In Figure 9, we show representative Rayleigh- and Love-wave dispersion curves (data and modeled). Previous studies illustrated that MASW using Love- and Rayleigh-wave dispersion data does not result in comparable velocity fields (Lowrie, 2007). This difference, in case of a landfill, was observed and discussed in Konstantaki et al. (2015a). In addition, discrepancies in the velocity values between the $V_{\mathrm{S}}$ field obtained from the reflection data and the ones obtained by MASW are expected as MASW does not take into account the localized scattered energy in the data (van Wijk and Levshin, 2004; Konstantaki et al., 2015a).

At shallow depths, the $V_{\mathrm{S}}$ obtained from MASW is higher than that obtained from the S-wave reflection data. It is, however, interesting to note that the overall distribution of the low- and highvelocity regions and the lower boundary of the surficial low-velocity region (indicated by the black line in Figure $8 \mathrm{a}$ and $8 \mathrm{~b}$ ) are similar between the velocity field obtained from the reflection data and that from MASW. Compared with Rayleigh-wave MASW, the result of MASW using Love-wave resembles more the velocity field obtained from seismic reflections. It was observed in Konstantaki et al. (2015a) that the vertical resolution of the velocity field in a landfill was higher in case of MASW using Love waves than using Rayleigh waves. The observed difference possibly comes from the broader frequency bandwidth that is available in case of dispersive Love waves (see Figure 9).

\section{Velocity field from early arrival waveform inversion}

For the near-surface region, early arrival waveform inversion is known to have performed better than the traveltime tomography. The results are generally more reliable (Sheng et al., 2006), and strong velocity variations are often more clearly imaged (Suroso et al.,

a)
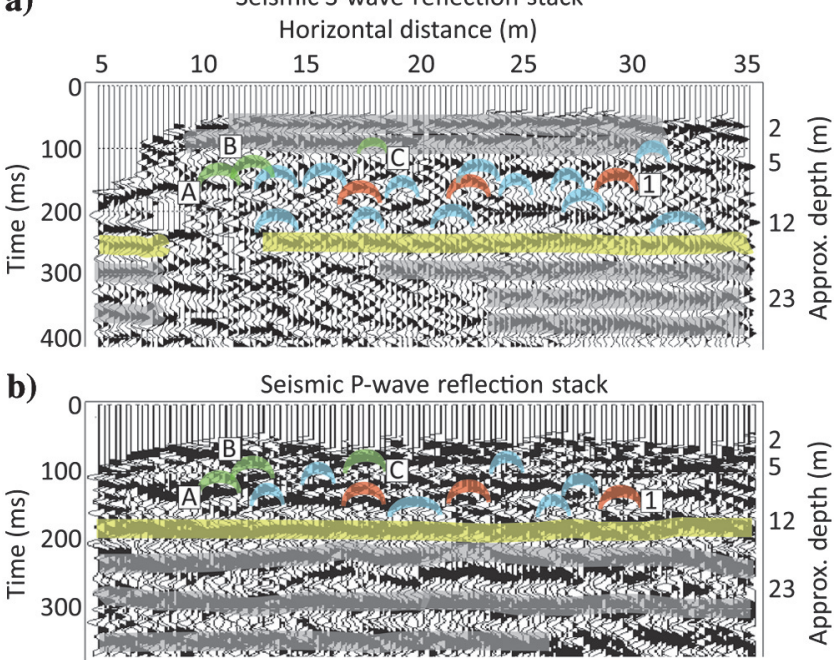

Figure 5. (a) Interpreted S-wave stacked section and (b) interpreted $\mathrm{P}$-wave stacked section. The red hyperbolae show scatterers that are almost at the same locations in both sections. Blue hyperbolae mark the remaining identified scatterers. Green hyperbolae correspond to events interpreted in Figure 6. The gray-shaded areas show reflectors. The bottom of the landfill is indicated by yellow.
2014). In our field data, the first arrivals are clearer in the P-wave data. The S-wave data showed strong surface-wave energy at early times that interfered with the first arrivals, and thus could not be effectively used for early arrival tomography. We carried out P-wave early arrival waveform inversion following Sheng et al. (2006). We used raw P-wave data for the picking of the first arrivals. Then, we picked the turning points of the first-arrival traveltimes in subshots (every $2.5 \mathrm{~m}$ ) to account for lateral heterogeneities. We used the turning point information to compute the initial velocity model. We applied top and bottom muting to the data to obtain a time window that includes only the early arrivals. The length of the time window beyond the picked first-arrival times was approximately $20 \mathrm{~ms}$. Because we used only first arrivals, attenuation was not addressed. The source wavelet was extracted for each shot separately, using a zero-offset extraction option. The extracted source wavelets were used in the inversion. The best results were obtained after 12 iterations, with a velocity-field smoothing parameter 0.5 and a maximum frequency of $35 \mathrm{~Hz}$ for the wavelet. The model roughness in the tomographic inversions is controlled by the smoothing parameter. The result is shown in Figure 10b. For a comparison, the velocity field obtained from the analysis of the P-wave reflection data is shown in Figure 10a. Note that the color scales are different between Figure 10a and 10b, to highlight the lateral velocity variations in the early arrival waveform inversion result. For our data set, early arrival waveform inversion could resolve the velocity field only down to $6 \mathrm{~m}$ depth. The estimated velocities are higher for the early arrival waveform inversion compared with the velocities from the reflection data. However, the lateral distribution and the vertical extent of the low- and high-velocity regions (indicated roughly by the black line in Figure 10) in the top part of the landfill are similar between the two results. Note that the black line here shows a lateral transition from high to low velocities that is observed in both $V_{\mathrm{P}}$ fields. A few localized events (dif-

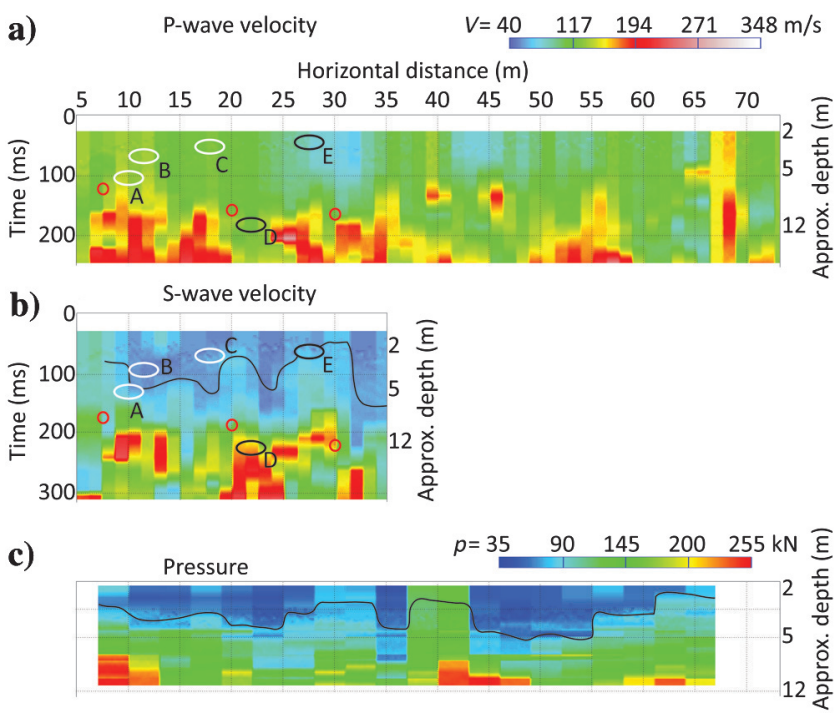

Figure 6. (a) The $V_{\mathrm{P}}$ field, (b) $V_{\mathrm{S}}$ field, and (c) mechanical tip-resistance pressure field of the landfill material. The white ellipses (A-C) indicate possible water or leachate-bearing zones; the black ones (D and E) - possible gas pockets. The black line in panel (b) marks tentatively the distribution of the lower limit of the lowrigidity zones at the shallow part of the landfill. The red circles show locations, for which the velocity analysis on CMP supergathers is illustrated in Figure 7. 
fractions) appearing in a later time window do not appear in P-wave early arrival times. This is responsible for the differences that we observe between Figure 10a and 10b. For instance, the detailed variations at $45-55 \mathrm{~m}$ horizontal distance and the high-velocity area localized approximately $68 \mathrm{~m}$ horizontal distance are not captured by the early arrival waveform inversion. However, the general similarity in the distribution of lateral heterogeneity resolved by early arrival waveform inversion and the velocity field obtained from P-wave reflection data offers confidence to our interpretation.

The $V_{\mathrm{P}}$ and $V_{\mathrm{S}}$ determined carefully by different approaches $\left(V_{\mathrm{P}}\right.$ from $\mathrm{P}$-wave reflection velocity analysis and $\mathrm{P}$-wave early arrival waveform inversion, $V_{\mathrm{S}}$ from $\mathrm{S}$-wave reflection velocity analysis, MASW using Love waves, and MASW using Rayleigh waves) are used to crosscheck the reliability of the heterogeneity distribution. This distribution, inferred from the seismic velocity fields, is important in the interpretation of wet and gassy (relatively dry, gas/air-filled) zones within the landfill.

\section{INTERPRETATION OF WET AND GASSY ZONES FROM P- AND S-WAVE VELOCITY FIELDS}

A landfill differs from natural soil. A heterogeneous landfill typically contains a distribution of relatively stiff and soft zones. The stiffer zones generally show up as scatterers in the seismic sections. These zones also act as obstruction to fluid flow. Konstantaki et al. (2015a) find low ER values above such scatterers, which were interpreted as relatively wet zones in the body of the landfill, created by obstruction of leachate flow due to the presence of stiffer object/area underneath. We have carefully looked at the P-and S-wave velocity fields (Figures 6, 9, and 10), in conjunction with the location of the distinct scatterers in stacked sections (Figure 5), to interpret wet and gassy zones in the landfill. Gassy zones in a landfill correspond to zones that are dry and have a higher concentration of gas/air compared with the wet zones.

The areas marked by A-C (white ellipses) in Figure $6 \mathrm{a}$ and $6 \mathrm{~b}$ are interpreted as zones in which a lateral transition from a dry to a relatively wet or water-bearing part/pocket of the landfill occur. This is because of the following two reasons. First, $V_{\mathrm{P}}$ clearly changes from a low to a high value within these areas (the width of the pixels in the velocity fields represents the distance between two consecutive CMP supergathers in the velocity analysis), whereas $V_{\mathrm{S}}$ remains nearly unchanged in the same unsaturated area. Second, we see distinct scatterers in the seismic sections (Figure 5), especially in the $\mathrm{S}$-wave stacked section, just below the higher $V_{\mathrm{P}}$ part in these areas, indicating a stiffer pocket. The $\mathrm{S}$-waves are more sensitive to the stiffness changes in the soil than P-waves.

Although elastic rigidity or shear modulus is hardly affected, the bulk density increases when going from a dry to a water-saturated region in the subsurface. As mentioned earlier, it is possible to get rid of the ambiguity due to density effect versus modulus effect by
S-waves

P-waves

a) Horizontal distance $=7.5 \mathrm{~m}$

Stacked

Velocity $(\mathrm{m} / \mathrm{s})$ Offset $(\mathrm{m})$ Stacked
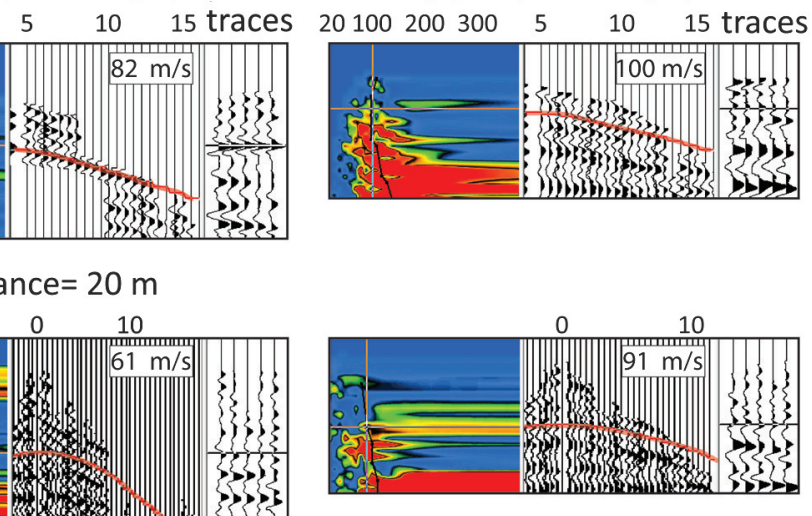

33,35

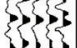

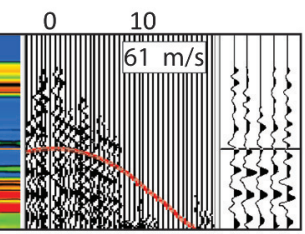

c) Horizontal distance $=30 \mathrm{~m}$
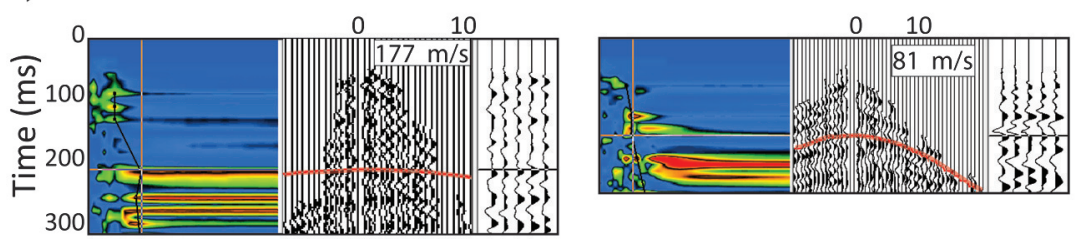

Figure 7. Examples of velocity analysis on $\mathrm{S}$ - and P-wave supergathers, showing abstacked traces are shown for each CMP supergather, as each supergather is composed of five adjacent CMP gathers.
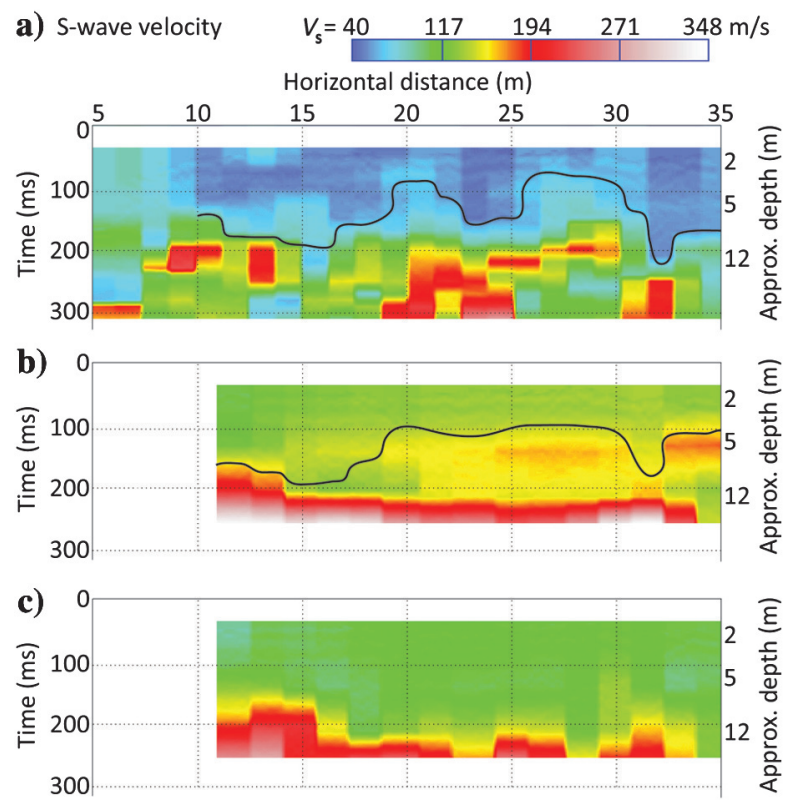

Figure 8 . The S-wave velocity field obtained from (a) S-wave reflection data, (b) MASW using Love, and (c) Rayleigh waves. The black line marks tentatively the lower limit of the shallowest lowvelocity zone. Note an approximately similar trend for this line, especially between panels ( $a$ and $b$ ). 
taking the $V_{\mathrm{P}} / V_{\mathrm{S}}$ ratio. In Figure $11 \mathrm{a}$, the $V_{\mathrm{P}} / V_{\mathrm{S}}$ distribution obtained from the seismic reflection data is shown. Because it is difficult to pick the velocity for the same depth region on P- and Swave refection data, in Figure 11a, the ratio has been estimated considering representative $V_{\mathrm{P}}$ and $V_{\mathrm{S}}$ values for different zones. In addition, as in Konstantaki et al. (2015a), a representative distribution of bulk density in the landfill was determined from the $V_{\mathrm{S}}$ field using a landfill-specific empirical correlation derived by Choudhury and Savoikar (2009) based on a large database of more than 30 different landfill surveys. The empirical equation is

$$
V_{\mathrm{S}}=\frac{1}{0.0174-0.000978 \gamma_{\text {waste }}},
$$

with $\gamma_{\text {waste }}$ being the unit weight of waste. Surface-wave methods and borehole seismics at landfill sites were mainly used for the $V_{\mathrm{S}}$ estimation. The result of applying the relationship to our data set (of $V_{\mathrm{S}}$ estimated from reflection data) is shown in Figure 11b. The estimated density values are within the range of the reported values for landfills (Leonard et al., 2000; EPA, 2008; WRAP, 2009). As the empirical relation is only valid for landfill materials, we calculate the density field only up to the interpreted bottom of the landfill in the seismic data (approximately $250 \mathrm{~ms}$ TWT) and not deeper. The empirical relationship is not valid for $V_{\mathrm{S}}$ lower than $50 \mathrm{~m} / \mathrm{s}$;

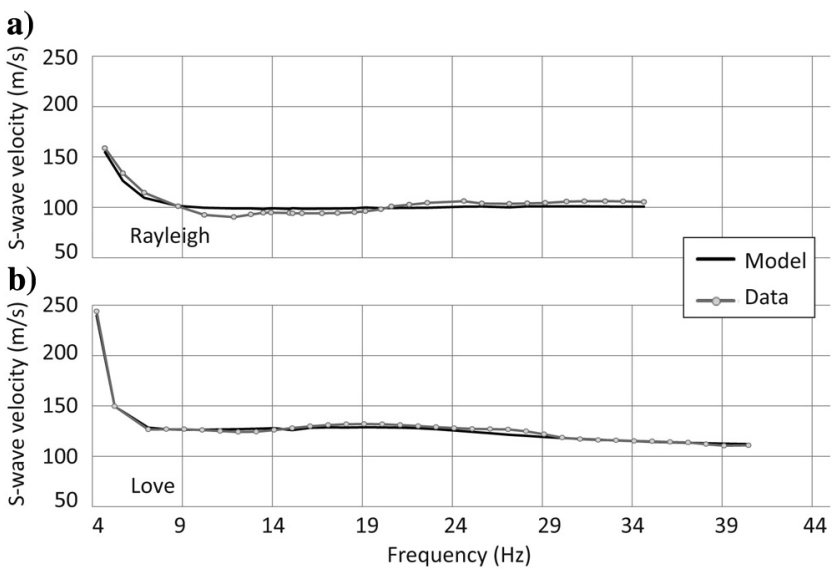

Figure 9. Representative dispersion curves for (a) Rayleigh- and (b) Love-waves. For these curves, the rms values are approximately $2 \%$ and $4 \%$, respectively.

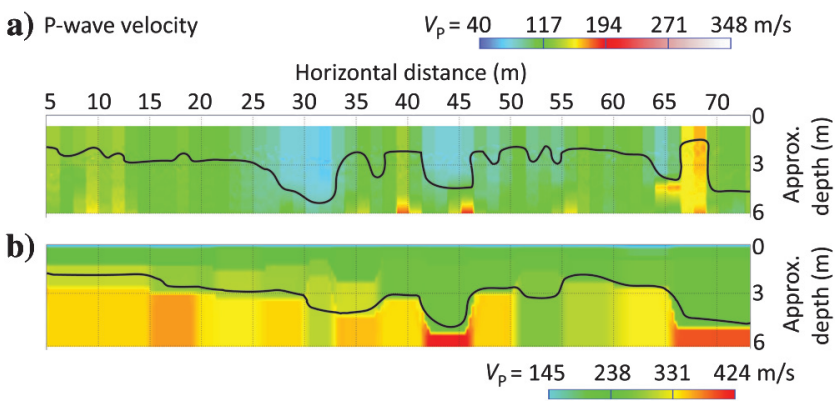

Figure 10. The $V_{\mathrm{P}}$ field obtained from (a) velocity analysis of $\mathrm{P}$-wave reflection data and (b) P-wave early arrival waveform tomography. The black line marks tentatively the lower limit of the shallowest low-velocity zone. therefore, we used a low cutoff for $V_{\mathrm{S}}$ when estimating the density. Because the relationship between $V_{\mathrm{S}}$ and density is nonlinear, a comparison between $V_{\mathrm{P}} / V_{\mathrm{S}}$ and density distributions offers useful insights. The A-C (white ellipses) in Figure 11a and 11b mark the same locations as in Figure $6 \mathrm{a}$ and $6 \mathrm{~b}$. At these locations, $V_{\mathrm{P}} / V_{\mathrm{S}}$ shows a transition from low to high values (Figure 11a), whereas the estimated bulk density shows rather low values, thus supporting the interpretation of wet zones for the part corresponding to relatively high $V_{\mathrm{P}} / V_{\mathrm{S}}$. Note that it is necessary to use $\mathrm{P}$ - and $\mathrm{S}$-wave velocity fields, $V_{\mathrm{P}} / V_{\mathrm{S}}$ and density distributions all together, to prevent faulty interpretations.

The areas marked by D and E (black ellipses) in Figure $6 \mathrm{a}$ and $6 \mathrm{~b}$ are interpreted as gas/air-bearing pockets. This is because at these locations $V_{\mathrm{P}}$ is dramatically lower than in the surrounding, whereas $V_{\mathrm{S}}$ is nearly unchanged or slightly increased. The $V_{\mathrm{P}} / V_{\mathrm{S}}$ is very low in part of these areas, and the estimated density should be much lower than the surrounding. The density field in Figure $11 \mathrm{~b}$ does not show a very low density at this location. This is because we have used an empirical relationship that does not take into account gassy/ air-filled zones. At horizontal distances between 26 and $34 \mathrm{~m}, V_{\mathrm{P}}$ is remarkably low and $V_{\mathrm{S}}$ shows no significant changes (Figure $6 \mathrm{a}$ and 6b). Furthermore, in this part, we see no dominant scatterers (Figure 5). Studies have reported that at gas-bearing zones, the seismic signal is weak (Missiaen et al., 2002). These are, therefore, all indications of the presence of relatively dry, gas/air-bearing zones. In our seismic data, very low $V_{\mathrm{P}}$ is observed approximately $2-5 \mathrm{~m}$ depth at horizontal distances 40-45, 48, 50-55, and approximately depth $11 \mathrm{~m}$ at 60-65 m horizontal distances (Figure 6a).

\section{VALIDATION USING MULTRIWELL DATA}

Multriwell performed biogas flow measurements at this site at two locations along a line parallel to and at approximately $11 \mathrm{~m}$ offset from our seismic lines (P. Hafkamp, personal communication, 2015): at -5 and $67 \mathrm{~m}$ horizontal distances. Their measurements show a much greater biogas flow at $67 \mathrm{~m}$ distance than at $-5 \mathrm{~m}$ distance. This is in agreement with our interpretations: We found no seismic indication of relatively dry, gas/air-filled zones at the beginning of our profile - at horizontal distances 5-15 m, whereas further along the line, and certainly approximately 60-66 m horizontal distances, $V_{\mathrm{P}}$ is extremely low, suggesting the possible presence of relatively dry zones.

The system measuring the mechanical resistance at the tip of a push devise by Multriwell B.V. is described earlier. The tip-resistance pressure of the waste in the landfill measured in shallow vertical wells positioned on a close grid was kindly made available to us. Figure $6 \mathrm{c}$ shows the tip-resistance pressure distribution derived from the data measured in 21 vertical wells along a line parallel and adjacent to (1-2 $\mathrm{m}$ distance from) our seismic line. At first sight, it is clear that the distribution of the low $V_{\mathrm{S}}$ (blue) areas in the landfill (Figure 6b) matches quite well with the distribution of the low mechanical tip-resistance (blue) areas of the waste (Figure 6c). Only at a few locations (e.g., at approximately $20 \mathrm{~m}$ horizontal distance) the match is not so good; this may be due to very localized heterogeneities that are seen differently along the two measurement lines (seismic and mechanical tip-resistance measurements), which are separated by a short, but nevertheless some, distance. Also note that around lateral distance $28-32 \mathrm{~m}$, the measured mechanical tipresistance pressure of the waste is very low. Based on our finding of a dramatically low $V_{\mathrm{P}}$, an almost unchanged $V_{\mathrm{S}}$ approximately 
26-34 m lateral distance (Figure 6a and 6b), and a remarkably low $V_{\mathrm{P}} / V_{\mathrm{S}}$ approximately $28 \mathrm{~m}$ (Figure $11 \mathrm{a}$ ), we interpret this area as to be more gassy/air-filled (relatively dry) than the surrounding. Very low mechanical tip-resistance pressure values found here appear to support this interpretation. At the locations of the interpreted wet zones in the landfill (e.g., A-C in Figures 6 and 11), the measured mechanical tip-resistance pressure is generally very low, though not as low as at the interpreted gassy/air-filled zones.

The correspondence between the distribution of $V_{\mathrm{P}}$ (Figure 6a) and that of the mechanical resistance pressure (Figure 6c) of the waste is slightly inferior to that between the distribution of $V_{\mathrm{S}}$ (Figure $6 \mathrm{~b}$ ) and the distribution of resistance. This can be explained by the fact that $V_{\mathrm{S}}$ is primarily controlled by rigidity of the waste skeleton, which is likely to be a strong determinant for the mechanical resistance. Better correlation between the tip resistance of cone penetration tests and $V_{\mathrm{S}}$ has been reported in previous studies, especially in a depth-specific sense (Ghose, 2012). On the other hand, the correlation that we observe between the distribution of $V_{\mathrm{P}}$ and that of the mechanical tip resistance of the landfill materials is determined by compressibility and density. In Figure 12, the result of regression analysis between our estimated seismic velocities (smallstrain property) and the measured mechanical tip-resistance pressure $p$ (large-strain property) in the landfill are shown. We used $V_{\mathrm{P}}, V_{\mathrm{S}}$, and the mechanical tip-resistance values at a given depth, to correct for the effect of vertical stress. The material properties that determine the value of these two quantities are not all common, which is partly responsible for the large scatter that we observe in Figure 12. Despite this larger scatter, $V_{\mathrm{P}}$ and $V_{\mathrm{S}}$ show a degree of correlation with the $p$. The correlation is slightly better and the slope of the best-fit line stiffer in case of $V_{\mathrm{S}}$, indicating a greater sensitivity to $p$ compared with $V_{\mathrm{P}}$. This finding will be useful in the future in characterizing landfills using seismic waves.

\section{DISCUSSION}

The seismic properties of a landfill deviate grossly from those of natural soils. The value of $V_{\mathrm{P}}$ in the landfill is found to be generally very low at this site. This could mainly be due to the fact that the pore spaces here contain gas/air, a fact well-known for this site. Presence of small amount of gas drastically reduces .

Although rare, very low values of $V_{\mathrm{P}}$ in unsaturated near-surface soil have been reported in a few earlier studies. Uyanik (2010) performs $\mathrm{P}$ - and $\mathrm{S}$-wave measurements in unconsolidated top soils and observed $V_{\mathrm{P}}$ lower than $330 \mathrm{~m} / \mathrm{s}$ in the very near surface. He finds $V_{\mathrm{P}} / V_{\mathrm{S}}$ as low as 1.5 and even lower. The theoretical lowest limit for $V_{\mathrm{P}} / V_{\mathrm{S}}$ is approximately 1.16 . Some other studies reported $V_{\mathrm{P}} \leq$ $330 \mathrm{~m} / \mathrm{s}$ and very low $V_{\mathrm{P}} / V_{\mathrm{S}}$ (Bachrach and Nur, 1998; Baker et al., 1999; Essien et al., 2014). Bachrach et al. (1998) find $V_{\mathrm{P}}$ less than $100 \mathrm{~m} / \mathrm{s}$ in beach sand. These low values were attributed to air-filled very shallow top soils or anisotropic materials.

Several earlier studies reported very low $V_{\mathrm{P}}$ in landfills. Abbiss (2001) finds $V_{\mathrm{P}}$ approximately $338 \mathrm{~m} / \mathrm{s}$. Frid et al. (2013) find occurrence of a low $V_{\mathrm{P}}$ zone due to strong waste disintegration. Golush (2008) concludes that in unsaturated landfills $V_{\mathrm{P}}$ values are lower than usual and that they are in the range of 180-700 m/s.

We attribute our observed very low $V_{\mathrm{P}}$ at the Twence site in the presence of gas/air-filled zones in the landfill. These zones may contain biogas that has migrated from lower areas in the landfill body. The equation of acoustic velocity for gasses is given by $V_{\mathrm{P}}=(\gamma R T / M)^{1 / 2}$, where $\gamma$ is the adiabatic constant, $R$ is the uni- versal gas constant $(8314 \mathrm{~J} / \mathrm{molK}), T$ is the absolute temperature (K), and $M$ is the molecular weight of the gas $(\mathrm{kg} / \mathrm{mol})$. The values of $\gamma$ and $M$ are specific for each gas type. The main components of the landfill biogas are methane and carbon dioxide. However, other gases and mixtures of gases are usually also present (Christensen et al., 1996). For carbon dioxide, $V_{\mathrm{P}}$ is less than $330 \mathrm{~m} / \mathrm{s}$. Considering representative values for carbon dioxide: $\gamma=1.3$, $M=44.01 \mathrm{~g} / \mathrm{mol}$, and $T=283.15 \mathrm{~K}$ (Jones, 1995; Kaye and Laby, 1995), we obtain $V_{\mathrm{P}}=263 \mathrm{~m} / \mathrm{s}$. Kaye and Laby (1995) re-
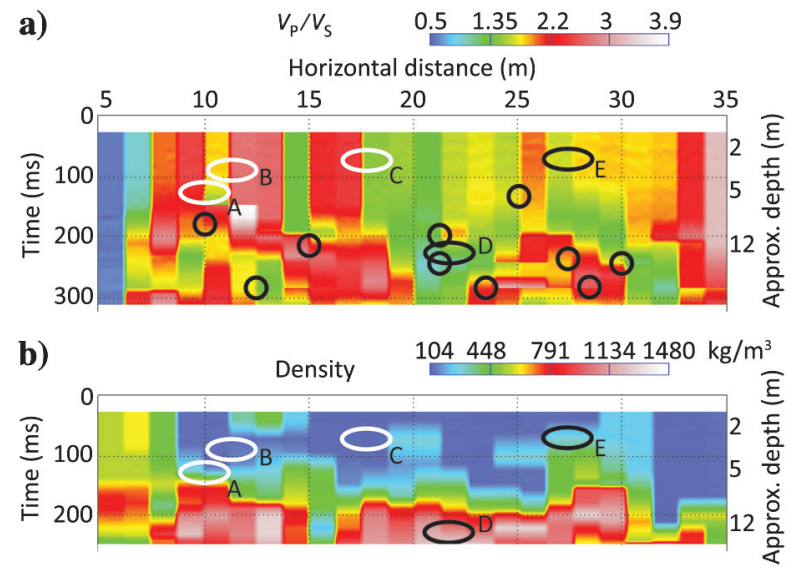

Figure 11. (a) The $V_{\mathrm{P}} / V_{\mathrm{S}}$ field and (b) density field. The white and black ellipses (A-F) are the same as those in Figure 6 and indicate the interpreted water-bearing and gas/air-bearing zones, respectively. The black circles mark locations where the velocity estimates are relatively uncertain.
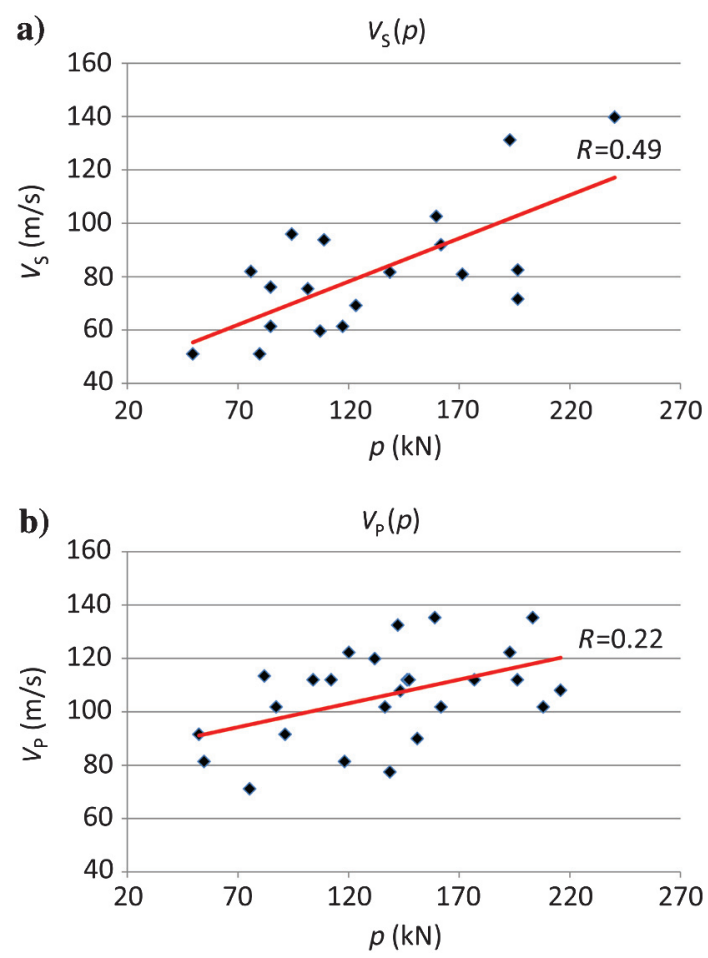

Figure 12. (a) Regression analysis between $V_{\mathrm{S}}$ and the mechanical tip-resistance pressure for waste deformation $p$, (b) regression analysis between $V_{\mathrm{P}}$ and $p$. 
port several gases with even lower acoustic velocities. The heterogeneous conditions in the landfill, presence of mixtures of gases, temperature variations, very soft soil conditions, and possible instabilities - all together can result in very low $V_{\mathrm{P}}$, as we observe in our study here.

An analysis using the Biot-Gassmann (Berryman, 1999) equations could allow for a better understanding of the low P-wave velocities, which could, in turn, further confirm the presence of a gaseous area or air-filled area. However, the Biot-Gassmann relations need information, such as porosity, bulk modulus of the solid material, or matrix of the landfill, and pore fluid bulk modulus that are not available to us. Assumptions can be made for these values, but this will translate into large uncertainties. A landfill is a very heterogeneous system and assumption on material present in it without actual ground truthing can be misleading.

Using only surface seismic measurements, it is challenging to resolve reliably the distribution of $V_{\mathrm{P}}$ and the $V_{\mathrm{S}}$ at shallow depths inside a heterogeneous landfill. In this vein, use of different methods for estimating the velocity fields is advantageous. In our study, $V_{\mathrm{P}}$ and $V_{\mathrm{S}}$ determined carefully by different approaches ( $V_{\mathrm{S}}$ from $S$-wave reflection velocity analysis and multichannel analysis of Love and Rayleigh waves), and they were used to crosscheck the heterogeneity distribution as inferred from the seismic velocity fields. This was important for interpretation of the wet and gassy zones within the landfill. As described before, velocity picking using only $\mathrm{S}$-waves or P-waves can result in erroneous velocity fields. This is because in our data, the S-wave reflections suffered at the far offsets from strong surface-wave arrivals, whereas P-waves did not provide sufficient resolution for identification of all scatterers in the near surface. In general, there is always a degree of uncertainty when picking the velocity using individual scatterers. The use of MASW and early waveform inversion method provides a check for the estimated velocity fields from $\mathrm{P}$ - and $\mathrm{S}$-wave reflection data.

Konstantaki et al. (2015a) highlight the importance of using more than one geophysical method in characterizing a landfill. When supplemented with $V_{\mathrm{P}}$ and $V_{\mathrm{S}}$ measurements, ER data can offer key information to constrain the interpretation of wet and gassy zones in a landfill. In addition, it has been shown recently that the use of seismic interferometry can not only improve the imaging of the landfill heterogeneity but it can also contribute to a better estimation of the velocity field (Konstantaki et al., 2013a, 2015b). The results obtained in this study will be further strengthened, if such complementary methods are available for delineating the wet and gassy zones in a heterogeneous landfill. The velocity models obtained from methods presented in this study can be improved in case a full-wave elastic inversion is performed. In that case, uncertainties due to erroneous picking can be minimized.

In the velocity analysis used for the reflection data, we have made a $2 \mathrm{D}$ approximation. It is likely that we record also signals from scatterers that are not directly below the seismic line, but are in the 3D surrounding. These arrivals may cause additional noise in conventional reflection data processing. It has, however, been shown recently that if seismic interferometry is applied to $3 \mathrm{D}$ ambient noise, the presence of scattered arrivals from the side can be of advantage in illuminating the landfill heterogeneities (Konstantaki et al., 2015b).

The results presented in this study illustrate the potential of using P- and S-waves reflection method for determining wet and gas-/airbearing pockets inside the landfill body. More consistent and sys- tematic interpretation should be possible in the future because more such seismic experiments are performed on landfills and more insights are obtained. As a next step, a 3D seismic reflection survey is recommended for the site to examine the entire volume of the landfill. That would provide a more complete picture to the landfill operator for efficient landfill treatment and biogas extraction. Determining heterogeneities with the seismic reflection method, as presented here, has earlier been successful in other landfill sites (Konstantaki et al., 2015a). Shallow seismic reflection methods can, therefore, be considered applicable in general to investigate any heterogeneous landfill site.

\section{CONCLUSIONS}

The distribution of the wet (leachate bearing) and gassy (relatively dry, gas/air-filled) zones in a landfill is needed for efficient treatment of the landfill and extraction of the biogas. We explored the possibility of characterizing the body of a heterogeneous landfill using seismic velocity information obtained from reflection, firstarrival waveform, and surface-wave dispersion data. From the obtained results the following conclusions can be drawn:

1) The $P$ - and $S$-wave reflection stacked sections image the landfill heterogeneities and bottom. Scatterers are imaged better by the $\mathrm{S}$-wave reflection data, due to the higher resolution of S-waves in soft materials and greater sensitivity.

2) The value of $V_{P}$ in the landfill was found to be generally very low at the site of our investigation. We attributed this primarily to the presence of biogas in the pore spaces of the landfill.

3) A combined interpretation of the $V_{\mathrm{P}}$ and $V_{\mathrm{S}}$ fields allowed for the definition of wet and gassy zones inside the landfill. Zones with a higher $V_{\mathrm{P}}$ compared with the surrounding, together with an unchanged to slightly lower $V_{\mathrm{S}}$, a relatively high $V_{\mathrm{P}} / V_{\mathrm{S}}$, low bulk density, and an occurrence of scatterer(s) underneath these locations as evidenced in the seismic data, were interpreted as wet (leachate bearing) zones. Gassy or air-filled pockets in the landfill were interpreted considering abnormally low value for $V_{\mathrm{P}}$ estimated from body- and surface-wave seismic data. These are zones with a lower $V_{\mathrm{P}}$ and a lower $V_{\mathrm{P}} / V_{\mathrm{S}}$ compared with the surrounding, unchanged to slightly higher value for $V_{\mathrm{S}}$, and absence of dominant scatterers.

4) Independent field measurements of biogas flow and mechanical tip resistance of the landfill (waste) material in shallow vertical wells were generally in agreement with our spatial delineation of stiff and soft zones, and interpretation of wet and gassy areas in the landfill based on seismic data. Compared with $V_{\mathrm{P}}, V_{\mathrm{S}}$ showed a better correlation with the data of independent measurements of tip resistance to waste deformation.

\section{ACKNOWLEDGMENTS}

This research is supported by the Dutch Technology Foundation (STW) under project number 11035. D. Draganov is supported by the Division for Earth and Life Sciences (ALW) with financial aid from the Netherlands Organization for Scientific Research (NWO). Seismic data are processed using Seismic Unix, the software package RadExPro and TomoPlus. We thank A. Hemstede, B. Boullenger, and P. Maas for their help in the acquisition of field data. Many thanks to R. Nijboer and M. Achtereekte (TWENCE) for allowing us to make the measurements on the landfill as well as 
H. Mulleneers (Trisoplast) and P. Hafkamp (Cofra) for providing us with the gas and mechanical tip-resistance data (Multriwell). The comments of four reviewers have helped in improving the manuscript.

\section{REFERENCES}

Abbiss, C. P., 2001, Deformation of landfill from measurements of shear wave velocity and damping: Géotechnique, 51, 483-492, doi: 10.1680/ geot.51.6.483.40461.

Angioni, T., R. D. Rechtien, S. J. Cardimona, and R. Luna, 2003, Crosshole seismic tomography and borehole logging for engineering site characterization in Sikeston, MO, USA: Tectonophysics, 368, 119-137, doi: 10 1016/S0040-1951(03)00154-9.

Bachrach, R., J. Dvorkin, and A. Nur, 1998, High-resolution shallow-seismic experiments in sand. Part II: Velocities in shallow unconsolidated sand: Geophysics, 63, 1234-1240, doi: 10.1190/1.1444424.

Bachrach, R., and A. Nur, 1998, High-resolution shallow-seismic experiments in sand. Part I: Water table, fluid flow, and saturation: Geophysics, 63, 1225-1233, doi: 10.1190/1.1444423.

Bacon, M., R. Simm, and T. Redshaw, 2003, 3-D seismic interpretation: Cambridge University Press.

Baker, G. S., D. W. Steeples, and G. Schmeissner, 1999, In-situ, highfrequency $\mathrm{P}$-wave velocity measurements within $1 \mathrm{~m}$ of the earth's surface: Geophysics, 64, 323-325, doi: 10.1190/1.1444537.

Barton, N., 2007, Rock quality, seismic velocity, attenuation and anisotropy: Taylor and Francis Group.

Berryman, J. G., 1999, Origin of Gassmann's equations: Geophysics, 64 1627-1629, doi: 10.1190/1.1444667.

Carpenter, P. J., K. R. Reddy, and M. D. Thompson, 2013, Seismic imaging of a leachate-circulation landfill: Spatial changes in dynamic properties of municipal landfill: Journal of Hazardous, Toxic, and Radioactive Waste, 17, 331-341, doi: 10.1061/(ASCE)HZ.2153-5515.0000175.

Choudhury, D., and P. Savoikar, 2009, Simplified method to characterize municipal solid waste properties under seismic conditions: Waste Management, 29, 924-933, doi: 10.1016/j.wasman.2008.05.008.

Christensen, T. H., R. Cossu, and R. Stegmann, 1996, Landfilling of waste: Biogas: E\&FN Spon, An imprint of Chapman and Hall.

EPA, 2008, Waste materials - Density data, http://www.epa.vic.gov.au/ business-and-industry/lower-your-impact/ /media/Files/bus/EREP/docs/ wastematerials-densities-data.pdf, accessed 10 January 2014.

Essien, U. E., O. Akankpo, and M. U. Igboekwe, 2014, Poisson's ratio of surface soils and shallow sediments determined from seismic compressional and shear-wave velocities: International Journal of Geosciences, 5, 1540-1546, doi: 10.4236/ijg.2014.512125.

Frid, V., A. Averbakh, and G. Liskevich, 2013, Integrated investigation of the instability-prone landfill site: Near Surface Geoscience 2013 - 19th EAGE European Meeting of Environmental and Engineering Geophysics, WES2A07, doi: 10.3997/2214-4609.20131418.

Ghose, R., 2003, High-frequency shear-wave reflections to monitor lateral variations in soil, supplementing downhole geotechnical test, in J. Saveur, ed., Reclaiming the underground space: Swets and Zeitlinger, 827-833.

Ghose, R., 2010, Estimating in situ horizontal stress in soil using time-lapse Vs measurements, in R. D. Miller, J. H. Bradford, and K. Holliger, eds., Advances in near-surface seismology and ground-penetrating radar: SEG, AGU, EEGS, 131-152, doi: 10.1190/1.9781560802259.ch8

Ghose, R., 2012, A microelectromechanical system digital 3C seismic cone penetrometer: Geophysics, 76, no. 1, T1-T11, doi: 10.1190/ geo2011-0266.1.

Ghose, R., and J. Goudswaard, 2004, Integrating S-wave seismic reflection data and cone-penetration-test data using a multiangle multiscale approach: Geophysics, 69, 440-459, doi: 10.1190/1.1707064.

Golush, T. V., 2008, Waste management research trends. Chapter 4: Contamination delineation and characterization of waste disposal sites performing integrated and innovative geophysical methods: Nova Publishers Inc. 221-259.

Johansson, S., H. Rosqvist, M. Svensson, T. Dahlin, and V. Leroux, 2011, An alternative methodology for the analysis of electrical resistivity data from a soil gas study: Geophysical Journal International, 186, 632-640, doi: 10.1111/j/1365-246X.2011.05080.x.

Jolly, J. M., R. P. Beaven, and R. D. Barker, 2011, Resolution of electrical imaging of fluid movement in landfills: Proceedings of the ICE Waste and Resource Management 164, 79-96, doi: 10.1680/warm 2011.164.2.79.

Jones, F. E., 1995, Density of gases - Techniques and topics in flow measurement: CRC Press Inc.

Kaye, G. W. C., and T. H. Laby, 1995, Tables of physical and chemical constants, 2.3.6: Specific heat capacities and 2.4.1: The speed and attenuation of sound: Kaye and Laby Online, Version 1.0 (2005), http://www. kayelaby.nlp.co.uk, accessed 8 April 2015.

Knight, R., and R. Nolen-Hoeksema, 1990, A laboratory study of the dependence of elastic wave velocities on pore scale fluid distribution: Geophysical Research Letters, 17, 1529-1532, doi: 10.1029/GL017i010p01529.

Konstantaki, L. A., S. Carpentier, F. Garofalo, P. Bergamo, and L. V. Socco, 2013b, Determining hydrological and soil mechanical parameters from multichannel surface-wave analysis across the Alpine Fault at Inchbonnie, New Zealand: Near Surface Geophysics, 11, 435-448, doi: 10.3997/ 1873-0604.2013019.

Konstantaki, L. A., D. Draganov, R. Ghose, and T. Heimovaara, 2013a, Imaging scatterers in landfills using seismic interferometry: Geophysics, 78, no. 6, 1-10, doi: 10.1190/GEO2013-0099.1.

Konstantaki, L. A., D. Draganov, R. Ghose, and T. Heimovaara, 2015b, Seismic interferometry as a tool for improved imaging of the heterogeneities in the body of a landfill: Journal of Applied Geophysics, 122, 28-39, doi 10.1016/j.jappgeo.2015.08.008

Konstantaki, L. A., R. Ghose, D. Draganov, G. Diaferia, and T. Heimovaara 2015a, Characterization of a heterogeneous landfill using seismic and electrical resistivity data: Geophysics, 80, no. 1, EN13-EN25, doi: 10 .1190/GEO2014-0263.1..

Leonard, S. M., J. K. Floom, and S. Brown, 2000, Estimating method and use of landfill settlement: Environmental Geotechnics, doi: 10.1061/ 40519(293)1.

Lowrie, W., 2007, Fundamentals of geophysics: Cambridge University Press.

Missiaen, T., S. Murphy, L. Loncke, and J.-P. Henriet, 2002, Very highresolution seismic mapping of shallow gas in the Belgian coastal zone Continental Shelf Research, 22, 2291-2301, doi: 10.1016/S0278-4343 (02)00056-0.

Nolasco, D., R. Noemí Lima, P. A. Hernández, and N. M. Pérez, 2008, Noncontrolled biogenic emissions to the atmosphere from lazaretto landfill, Tenerife, Canary Islands: Environmental Science and Pollution Research, 15, 51-60, doi: 10.1065/espr2007.02.392.

Overzet, D., and H. Woelders, 2013, Results of additional vertical gas extraction system in old landfill (Multriwell): Presented at the 14th International Waste Management and Landfill Symposium.

Park, C. B., R. D. Miller, and J. Xia, 1999, Multichannel analysis of surface waves: Geophysics, 64, 800-808, doi: 10.1190/1.1444590.

Rojas, E., T. L. Davis, M. Batzle, M. Prasad, and R. J. Michelena, 2005 $V_{\mathrm{P}}-V_{\mathrm{S}}$ ratio sensitivity to pressure, fluid, and lithology changes in tight gas sandstones: 75th Annual International Meeting, SEG, Expanded Abstracts, 1401-1404.

Rosqvist, H., T. Dahlin, and C. Lindhé, 2005, Investigation of water flow in a bioreactor landfill using geoelectrical imaging techniques: Proceedings Sardinia 2005, 10th International Waste Management and Landfill Symposium, 3-7.

Rosqvist, H., V. Leroux, T. Dahlin, M. Svensson, M. Lindsjö, C.-H. Mansson, and S. Johansson, 2011, Mapping landfill as migration using resistivity monitoring: Waste and Resource Management, 164, 3-15, doi: 10 .1680/warm.2011.164.1.3

Scharff, H., J. Jacobs, H. Oonk, and A. Hensen, 2011, Methods to ascertain methane emission of landfills: Online report, http://www.afvalzorg.nl/EN/ About-us/Publications/Methane-emissions.aspx, accessed 3 March 2015

Sheng, J., A. Leeds, M. Buddensiek, and G. T. Schuster, 2006, Early arrival waveform tomography on near-surface refraction data: Geophysics, 71, no. 4, U47-U57, doi: 10.1190/1.2210969.

Sormunen, K., M. Ettala, and J. Rintal, 2008, Internal leachate quality in a municipal solid waste landfill: Vertical, horizontal and temporal variation and impacts of leachate recirculation: Journal of Hazardous Materials, 160, 601-607, doi: 10.1016/j.jhazmat.2008.03.081

Sponza, D. T., and O. N. A ğdağ, 2004, Impact of leachate recirculation and recirculation volume on stabilization of municipal solid wastes in simulated anaerobic bioreactors: Process Biochemistry, 39, 2157-2165, doi: 10.1016/j.procbio.2003.11.012.

Suroso, T., T. B. Nugraha, S. Harmini, L. Novitasari, and H. Winarto, 2014, Near surface imaging using early arrival waveform tomography: A carbonate reservoir: Abstract Proceedings, Pit Hagi, 39.

Themelis, N. J., and P. A. Ulloa, 2007, Methane generation in landfills: Science Direct, Renewable Energy, 32, 1243-1257, doi: 10.1016/j.renene .2006.04.020.

Timmermans, E., and T. Hilebregt, 2012, A new, effective solution for landfill gas extraction: Presented at the Fachtagung "Die sichere Deponie 2012 - Sicherung von Deponien und Altlasten mit Kunststoffen": SKZ - ConSem GmbH, Würzburg und AK GWS Arbeitskreis Grundwasserschutz e. V.

Uyanik, O., 2010, Compressional and shear-wave velocity measurements in unconsolidated top-soil and comparison of the results: International Journal of the Physical Sciences, 5, 1034-1039.

Van Wijk, K., and A. L. Levshin, 2004, Surface wave dispersion from small vertical scatterers: Geophysical Research Letterers, 31, L20602, doi: 10 .1029/2004GL021007. 
Westbrook, G. K., S. Chand, G. Rossi, C. Long, S. Bünz, A. Camerlenghi, J. M. Carcione, S. Dean, J.-P. Foucher, E. Flueh, D. Gei, R. R. Haacke, G. Madrussani, J. Mienert, T. A. Minshull, H. Nouzé, S. Peacock, T. J. Reston, M. Vanneste, and M. Zillmer, 2008, Estimation of gas hydrate concentration from multi-component seismic data at sites on the continental margins of NW Svalbard and the Storegga region of Norway: Marine and Petroleum Geology, 25, 744-758, doi: 10.1016/j.marpetgeo.2008.02 .003 .

WRAP, 2009, Summary report - Material bulk densities, resource futures, http://www2.wrap.org.uk/downloads/Bulk_Density_Summary_ Report_Jan2010.fc38a386.8525.pdf, accessed 10 January 2014. 